\title{
Risk-Adjusted Analysis of Relevant Outcome Drivers to Patients with Diabetes
}

\author{
Zaqqi Ubaidillah*, Yulia Yulia, and Henny Permatasari \\ Department of Nursing, Faculty of Health Sciences, University of Muhammadiyah Malang, Indonesia \\ Jalan Bendungan Sutami 188 A, Kota Malang, Jawa Timur, 65145 \\ *Corresponding author: zaqqi.ubaidillah@gmail.com
}

\begin{abstract}
Background: Clients with diabetes are particularly at high risk of traffic accidents that might be caused by the acute complications such as, hypoglycemia and hyperglycemia as well as chronic complications such as, micro-vascular diseases, macro-vascular diseases and neuropathy. Objectives: This study aimed to get an in-depth understanding about the experience of diabetic clients during driving car or riding motorcycle at Depok city. Method: Six participants were recruited using a purposive sampling method. A Colaizzi content analysis was employed. Results: Seven Themes emerged depicted the meaning of experiences of driving among DM clients. The seven themes were interdependence. Conclusion: This study concluded that diabetes clients who actively drive had high risk of having road accident. This study suggested the necessity of regulation and education for clients with diabetes who actively drive.
\end{abstract}

Keywords: Diabetes Client, Driving, Accident Risk, Theme, Regulation And Education

\section{INTRODUCTION}

Driving a vehicle is a complex activity, requires roommates' vigilance, strength, physical coordination, agility, judgment, attention, knowledge, and skill (CDMV, 2011). Therefore, the general public able to the risk of a traffic accident caused by the fact that the character of the traffic is closely related to the speed, character and behavior of the driver (age, gender, alcoholics and seatbelt use). A changed in average speed of $1 \mathrm{~km} / \mathrm{h}$ will result in a change in accident numbers ranging between $2 \%$ for a $120 \mathrm{~km} / \mathrm{h}$ road and $4 \%$ for a 50 $\mathrm{km} / \mathrm{h}$ road. This result has been confirmed by many before and after studies of different speed reduction measures. This relationship is used by other Scandinavian countries and by Australian and Dutch safety engineers. A similar relationship is assumed in Britain, based on empirical studies by Taylor, where changes in accidents have been shown to vary between $1 \%$ and $4 \%$ for urban roads and $2.5 \%$ and $5.5 \%$ For rural roads, with the lower value reflecting good quality roads and the higher value poorer quality roads. It can assume that 1 $\mathrm{km} / \mathrm{h}$ Increase in speed \& racer can increase of about 3\% in accidents (EC, 2010).

Meanwhile a traffic accident on a client with diabetes, which can be caused by acute complications i.e.; Hypoglycemia and hyperglycemia; Chronic complications ie; microvascular disease, macrovascular disease and neuropathy (Dunning, 2009). The state of hypoglycemia can cause impaired decision making to cause impaired motor cognitive function, impaired decision making, vision changes and even coma risk. This was supported in a study of 452 drivers with type 1 diabetes who were studied for 12 months, found that 185 of participants $(41 \%)$ had moderate hypoglycemia 503 times and 23 of participants $(5 \%)$ had severe hypoglycemia 31 times (Cox et al., 2009)

Moreover, drivers with DM are at risk of drowsiness during driving. This conclusion was obtained in 4540 respondents, a total of 470 respondents who had diabetes, found that 
the ratio occurred mildly drowsy during the drive of 0.41 and moderate to heavy drowsy of 2.97 (Hayashino, Yamazaki, Nakayama, Sokejima, \& Fukuhara, 2008).

The high traffic congestion at Depok City can provide a negative impact. because the travel time becomes longer. It increases risk hypoglycemia state because blood glucose is continuously reduced and can also be due to side effects of client diabetes therapy. Those condition can be harmful even crashing during driving a vehicle.

Furthermore, In Indonesia, there has been no attempt by the police to regulate standard criteria for obtaining driver's licenses for people with diabetes.

Until recently, little attention has been given to driver with diabetes, there are few publications concerning this issue, there is no promotion for it and there is no regulation particularly in Indonesia. This study was conducted to explore and get immerse understandable the experience of diabetes client on driving at Depok City.

\section{METHOD}

This study used qualitative phenomenology method approach. Sample selection by purposive sampling. Data analysis by colaizzi approach

\section{RESULT AND DISCUSSION}

Representative of the meaning contained from the experience of driving on DM clients. The seven themes are:

\section{Theme 1: Blood glucose levels, neuropathic complications and sleeping time are not adequat lower driving control;}

There are some conditions. This theme has several subthemes, among others, decreased coordination control, slowed body response, fatigue, lack of adequate sleep, street drowsiness, changes in sensory perception function, impaired glucose metabolism and circulatory disorders. Decreased coordination control at high blood sugar levels while driving. Participant six told once driving a car to the market week, when the participants in a driving position and the car in the running state. Then, suddenly the participant seems to lose control of the steering wheel for a few minutes, so the filing had to stop the car for a few minutes to recover. After the incident, participants checked their blood sugar of $450 \mathrm{mg} / \mathrm{dl}$. This is evidenced by the following statement

"... ever when driving suddenly I like a dizzy (like unconscious) like losing control, lost consciousness for a few minutes, it turns out after checked 450 blood sugar ..." (p.6, 96th line)

From participant statement, she loses control a few second while driving, and as soon as possible she stops her car, then continue drive after her condition was stable. In addition, the slowed body response can affect driving control, especially in the brake and control of the steering wheel. One participant (P1) felt that the body's response slowed down on the brake before it was diagnosed with diabetes. Thus, the participants on the brake suddenly responded slowly. In addition, people said that to make a steering wheel should avoid objects in front of him suddenly a little late because of physical movement has decreased.

Later, four participants (p1, p2, p4 and p5) Said that people with diabetes tend to be more easily tired during the activity of one of them driving. Participants 4 and 5 add that they feel more tired doing the driving activity after doing the activity before driving like after work. Then, drowsiness while doing driving activities also affect in controlling the vehicle. The six participants said they had experienced sleepiness while driving with different causes. P2, p3, p4 and p5 says that one of the causes of sleepiness when driving is sleep deprivation. 
Participant two stated that his sleep deprivation was due to his self-awareness to wake up for night prayer and sometimes it was hard to sleep again after waking up in the middle of the night as experienced by three, four and five participants. P5 added that sometimes the lack of sleep caused due to frequent night urination that sometimes almost five times a night. Lack of sleep at night can affect safety and safety in driving. In addition, drowsiness while driving can decrease concentration. This happened to the participant one had hit the car in front of him when sleepy and the four participants never hit the power pole due to sleepy when driving. According to almost all participants said that people with diabetes are prone to sleepiness even when driving. Participants one, three, four and five often experience drowsiness while driving, even participants one, three and four had to fall asleep in the car, while the five participants are often also suffering from drowsiness when riding a motorcycle. In addition, participants stated that the tendency of drowsiness and fatigue quickly caused by high blood sugar. Participants one, four, five and six stated that at the time of high blood sugar that is, blood sugar levels more than $200 \mathrm{mg} / \mathrm{dl}$ susceptible to drowsiness. Participants four and five add that in addition to the feeling of sleepiness, they feel more tired when their blood sugar is high.

\section{Theme 2: Decreasing physical strength and visual response at night decreases driving adaptation.}

The second theme is some conditions that can decrease the adaptation of the drive. The condition in question is, the visual disturbance at night and the decrease of physical condition. Participants recounted that their visual acuity tends to be disturbed or to feel blurred during nighttime driving. This is said by participants two and five that their views are very disturbed when driving at night, especially when exposed to the lights of cars or motorcycles on the road. A statement that supports that participants experience decreased night vision sharpness is,

"... the view of night blur, if my night view is not so bright as during the day, especially there is a flashing light ..." (p.5, 44th line)

\section{Theme 3: Efforts to overcome sleepiness in the middle of driving with heating, walking and sleeping in the car}

There were five participants (P1, P3, P4, P5 and P6) suggesting that they sometimes experience sleepiness when driving. The five participants said that if there is sleep suddenly on the road pulled over for a moment to eliminate sleepiness and after sleep lost new resume journey.There are various ways that participants do to eliminate drowsiness. Participant one recounts when the drowsiness occurs, the participant pulls over in any place that can be made to park the car, then participants get off the car and walk about 10 minutes and resume their journey or participant drink coffee or eat snacks. Participant three slightly different that is, participants pulled aside then sleep for a moment about 15 minutes new resume journey after waking up. Four participants stated that they had to rest for a while in the mosque or places that could be made for parking for a moment or the participants diverted by listening to music or eating snacks like peanuts. Participant five stated that if drowsiness had to pull over first and do the movement of warming or muscle or basic movement of exercise. Then participant six, stating that if the drowsiness sleep should be a short break. Like the following statement:

"... I pulled over to find a street that I can pull over, yaw dah I keep this I rest for a while I sleep for 15 minutes so ..." (p.3, line 34) 


\section{Theme 4: Precautions of hypoglycemia, consumption of $\mathrm{OHO}$ and measuring physical strength become routine preparation before driving}

Precautions hypoglycemia conducted by participants before driving, namely setting the diet before and while driving. There were two participants who discussed dietary arrangements before driving, ie, participants one and three. According to participants one, eating before driving did not eat too much, adjusted to the diabetic diet rules that have been educated by a doctor. Meanwhile, participants three told me if you have to regulate the daily diet that is, reduce the consumption of foods that contain lots of carbohydrates and consume foods that contain lots of protein. It is intended that participants do not find obstacles while driving. In addition, participants also always bring snacks made with their own recipe in accordance with the diabetes diet that is, food containing a little glucose. The food is brought with the purpose of food supply if in the middle of the road participants feel weak because of hunger. This is in accordance with the following statement:

".... I always drive there food so yes, I put the food so, for example I am limp, I eat and drink so for example cookies, I make my own, with our own recipe, with not too much sugar, salty, so I make Kastengo, sometimes cashew nut. I pour a little salt in cashew nut so there is salty ya ... "(p.3, 55th line)

\section{Theme 5: Exercise provides the benefits of maintaining physical fitness and preventing drowsiness while driving}

Four participants (P2, P5 and P6) said that regular exercise can maintain physical conditions while doing the driving activity. Participant two said that if it must be active to drive should keep his condition by doing sports. Participant three tells us that driving activities are no longer a constraint if increasing sport activities. Participants five said that if exercise regularly can keep the physical condition is good and not easy to get sleepy when driving. Then, Participant six tells if regular exercise can increase stamina in performing daily activities including driving activities. Like the following statement:

"... with this warming movement I can do to help me for activities including cooking, work and driving too, sports can increase my stamina while driving ..." (p.6, 74th line)

\section{Theme 6: Self-management of diabetes that has been done by the client.}

Various efforts in diabetes management independently that has been done by participants. Various responses are conveyed by each participant and the thoughts they share in accordance with the knowledge they get from both health workers and the results of their own reading. The disclosed diabetes management subscheme of this theme, among others, drug management, sports management, diet management, education and therapy modalities and prevention and treatment. In addition, participants also said there were some obstacles in the management of diabetes, among others, disobedience in the management of treatment and non-compliance in the management of diet.

The first management of diabetes is the management of drugs. The six participants of diabetes drugs consumed varied depending on the duration of their diabetes. Participants one and five said they were taking diabetes drugs the morning before eating and drinking again at night. Meanwhile, participants two and three said that taking the medicine once just the morning before eating. As for the type of diabetes drugs consumed by each participant ie, the participants consumed Metformin and Glimpirid and had a history of insulin users, the participants took Metformin and Glucobide, the participants took Glukomik, four took Metformin and Glibidon, the participants consumed Metformin, diamegron and 
glibenclamide, six participants took metformin and glibenclamide. The supporting statements are as follows:

"... I said I should take medication, take some medicine, it should be breakfast yes breakfast, exercise my routine morning exercise, walking.... every day about 2 kilometers sometimes 1 kilometers..." (p.2, line 108)

\section{Theme 7: Regulations and education needed by an active diabetes client driving to improve driving safety.}

The form of rules and education desired by the participants is based on participants' ideas according to the personal phenomenon and experience of the participants. The hope is directed to health workers and police agencies.

"... it must be provided a actual health test, from the eyes, from blood sugar, the blood tension must be checked properly, is he worthy or not to get driver's license..." (p.3 line 158)

The body's response slows down when stepping on the brakes or in controlling the steering wheel. It is based on what P1 expressed. Diabetic clients have a tendency to respond slowly when doing movement against stimulus when driving. The slow reaction is related to neurological complications caused by diabetes that is, neuropathy resulting in a decrease in peripheral nerve conduction velocity (Richerson, Robinson, \& Shum, 2005). Retinopathy can decrease the field of view of the rider, which may lead to the risk of an accident. Based on the study said that people with visual field reduction at risk of an accident while driving (OR 3.6, 95\% CI 1.4-9.4 and OR 4.4, 95\% CI 1.6-12.4) compared with those who did not experience a decrease in the visual field (McGwin et al., 2005).

The relationship between hyperglycemia with the onset of retinopathy is explained by several biochemical reactions approach one of them is the hexosamine pathway. Hyperglycemia can increase the metabolism of the hexosamine pathway. Hexosamine rising levels in tissue of the retina in people with diabetes. Normally, if there is a $3 \%$ glucose in the cells enter the hexosamine pathway to synthesize UDP-N -acetylhexosamine (UDPHexNAc), namely, an important substrate for the synthesis of glycosyl side chains of protein and fat. However, small amounts of glucose change in these pathways can have a variable effect on the function of proteins such as interfering with insulin receptors in the retina. This is believed to be the potential occurrence of retinopathy in diabetic client (Giacco \& Brownlee 2010 ; Ola, Nawaz, Siddiquei, Al-Amro, and Abu El-Asrar, 2012).

Hypoglycemia can cause visual impairment because it disrupts the visual pathway of the central nervous system or leads to a decrease in the function of the eye and binoculars. The study says that impaired vision due to hypoglycemia caused by nerve pathways neuroglycopenia at the visual center of the refraction function changes or abnormalities of binocular eye (Tabandeh, Ranganath, \& Marks, 1996). The binocular view of the eye is the process of producing one image of two different images of each monocular view (one eye view). This is to be get clear images and deeper perception of the image so that the nervous system makes it possible to perceive objects in three-dimensional space and can estimate the distance how far objects are seen (Dragoi, 2007). Thus, it can be concluded if the occurrence of such disturbances can lead to people driving not able to measure the distance approximately from the objects around him.

Peripheral circulation disturbances or sensations that occur in participants ie, cramps and numbness at the time of driving. Circulatory and sensory disorders can threaten DM clients in driving because they can reduce and / or eliminate sensory, especially on peripheral nerves such as the feet and hands. This is what can cause an interruption in driving because of 
the absence of sensory peripheral nerves can decrease client response in the brake pedal and may not even be able to control the speed (Stork, Haeften, \& Veneman, 2006; HHP, 2012).

Fatigue in diabetes clients while driving can be caused by impaired glucose metabolism. The metabolic disorder caused by the lack of uptake of glucose by the body cells (Brunner, Smeltzer, Bare, Hinkle, \& Cheever, 2010). The low amount of insulin circulating in the body's circulatory system or insulin resistance required for the transport of glucose to the cell, very low blood glucose levels or overdose of diabetes drugs result in cells not getting adequate glucose intake and energy deficient bodies that ultimately lead to physical weakness, tired and sleepy (Brunner et al., 2010; Diabetes.co.uk, 2014). Sleepiness when driving can also be caused by changes in sleep patterns and polyuria during the night. This is based on studies of 74 diabetes and 32 non-diabetics compared to their sleep-wake cycle, the results showed that diabetes clients significantly experienced an irregular sleep-wake cycle compared to non-diabetes and the prevalence of daytime drowsiness by $46 \%$ in client's diabetes and $22 \%$ in non-diabetic (Nakanishi-Minami, Kishida, Funahashi, \& Shimomura, 2012).

Sensory perception disturbances are, decreased vision, especially at night. Based on data obtained from the participants said that driving at night vision is less clear, especially when exposed to the headlights. This is possible due to diabetic retinopathy. Two early signs of diabetic retinopathy was reduced view at night and it took a long time to see normally if the eye is exposed to light (Brian \& Wachler, 2013). Prevention efforts anticipate the occurrence of metabolic disorders. Meanwhile, when driving participants said that if sleepy irresistible pull over, stop for a moment, stretch the body or stretching and there is also a short nap in the car. Walking for a moment can increase the burning of blood glucose and blood flow as well. Based on research on 39 type two diabetes around the age of 63 shows that there is a decrease in blood glucose of $2.2 \mathrm{mmol} / 139.64 \mathrm{mg} / \mathrm{dl}$ after walking half an hour intervention (Rosenqvist, 2001).

Benefits of sports according to participants that is, can maintain fitness when doing driving activities. Based on research conducted on 32 people with age range 60-80 years with intervention with regular exercise 60 minutes / week for 12 weeks showed that exercise can provide benefits increase reaction time, movement time, and response time (single task or two); Improve the speed of the visual process and attention; Improve psychomotor performance in lower extremities. The results of these studies concluded that exercise can improve performance and increase the safety of driving ability (Marmeleira, Godinho, \& Fernandes, 2009). Based on the recommendation of American Diabetes association (2014) there are four main actions in improving driving safety in DM clients such as identifying and evaluating DM clients who have driver's license, driving license decision based on evaluation result, health and education personnel report and Clinical intervention.

\section{CONCLUSION}

There are two conditions that can provide an accident risk when driving, i.e., blood glucose levels of neuropathy complications and sleeping time that does not adequate lower driving control; Decreased physical strength and visual response at night decreases driving adaptation. However, based on these constraints the client without realizing already doing physical preparation such as, eat sufficiently before driving. Although, they have never been informed about the risk of driving for diabetic clients. However, participants were able to manage diabetes well enough because knowledge about diabetes management was good enough from diabetes seminars, Persadia, health workers and also looking for themselves. The management knowledge that most participants get through Persadia friends who exchange information and also seminars. 
Participants' expectations of health and police personnel, among others, health workers should provide an integrated education of driving safety guidelines for active diabetes clients driving, such as, what range of blood glucose levels are safe for driving. Furthermore, the police agency is expected to evaluate the provision of SIM to the diabetes client both during the test and also the extension of the MIS to always be evaluated health.

\section{REFERENCES}

Brian, \& Wachler, Boxer. (2013). Night vision problems: halos, blurred vision, and night blindness. Retrieved from http://www.webmd.com/eye-health/night-vision-problemshalos-blurred-vision-night-blindness

Brunner, L.S., Smeltzer, S.C.O.C., Bare, B.G., Hinkle, J.L., \& Cheever, K.H. (2010). Brunner \& Suddarth's Textbook of Medical-surgical Nursing. New York: Wolters Kluwer Health / Lippincott Williams \& Wilkins.

CDMV, California Department of Motor Vihicles. (2011). Driver Safety Information Medical Conditions and Traffic Safety State of California Retrieved from http://www.dmv.ca.gov/dl/driversafety/dsmedcontraffic.htm .

Cox, Daniel J., Ford, Derek, Gonder-Frederick, Linda, Clarke, William, Mazze, Roger, Weinger, Katie, \& Ritterband, Lee. (2009). driving mishaps among individuals with type 1 diabetes: a prospective study. Diabetes Care, 32(12), 2177-2180.

Diabetes.co.uk. (2014). Tiredness and Diabetes. Retrieved from http://www.diabetes.co.uk/tiredness-and-diabetes.html

Dragoi, Valentin. (2007). Visual processing: eye and retina. Retrieved from http://neuroscience.uth.tmc.edu/s2/chapter14.html

Dunning, T. (2009). Care of people with diabetes: a manual of nursing practice (third ed.). west sussex, UK: Jhon Wiley \& Sons.

EC, European Commission. (2010). Mobility and transport road safety speed and the injury risk for different speed levels. Retrieved from http://ec.europa.eu/transport/road_safety/specialist/knowledge/speed/speed_is_a_centra 1_issue_in_road_safety/speed_and_the_injury_risk_for_different_speed_levels.htm .

Giacco, F., \& Brownlee, M. (2010). Oxidative stress and diabetic complications. Circ Res, 107(9), 1058-1070. doi:10.1161 / circresaha.110.223545

Hayashino, Y., Yamazaki, S., Nakayama, T., Sokejima, S., \& Fukuhara, S. (2008). Relationship Between Diabetes Mellitus and Excessive Sleepiness During Driving. Exp Clin Endocrinol Diabetes, 116(EFirst), 1-5. doi: 10.1055/s-2007-984442

HHP, Harvard Health Publications. (2012). Diabetes: A plan for living. Norwalk: Belvoir Media Group, LLC.

Marmeleira, José F., Godinho, Mário B., \& Fernandes, Orlando M. (2009). The effects of an exercise program on several abilities associated with driving performance in older adults. Accident Analysis \& Prevention, 41(1), 90-97. doi:10.1016/j.aap.2008.09.008

McGwin, Gerald, Xie, Aiyuan, Mays, Andrew, Joiner, Wade, DeCarlo, Dawn K., Hall, Tyler Andrew, \& Owsley, Cynthia. (2005). Visual field defects and the risk of motor vehicles collisions among patients with glaucoma. Investigative Ophthalmology \& Visual Science, 46(12), 4437-4441. doi:10.1167 / iovs.05-0750

Nakanishi-Minami, T., Kishida, K., Funahashi, T., \& Shimomura, I. (2012). Sleep-wake cycle irregularities in type 2 diabetics. Diabetol Metab Syndr, 4(1), 18. doi:10.1186 / 1758-5996-4-18

Ola, Mohammad Shamsul, Nawaz, Mohd Imtiaz, Siddiquei, M. Mairaj, Al-Amro, Saleh, \& Abu El-Asrar, Ahmed M. (2012). Recent advances in understanding the biochemical 
and molecular mechanism of diabetic retinopathy. Journal of Diabetes and its Complications, 26(1), 56-64. doi:10.1016/j.jdiacomp.2011.11.004

Richerson, SJ, Robinson, CJ, \& Shum, J. (2005). A comparative study of reaction times between type II diabetics and non-diabetics. Biomed Eng Online, 4(12). doi:10.1186 / $1475-925 x-4-12$

Rosenqvist, Tomas Fritz, Urban. (2001). Walking for exercise? Immediate effect on blood glucose levels in type 2 diabetes. Scandinavian Journal of Primary Health Care, 19(1), 31-33. doi: 10.1080 / pri.19.1.31.33

Stork, Alexander DM, Haeften, Timon W. van, \& Veneman, Thiemo F. (2006). Diabetes and driving desired data, research methods and their pitfalls, current knowledge, and future research. Diabetes Care, 29(8). doi: 10.2337 / dc05-2232

Tabandeh, H., Ranganath, L., \& Marks, V. (1996). Visual function during acute hypoglycaemia. Eur J Ophthalmol, 6(1), 81-86. 